\title{
Quantifying pollution inflow and outflow over East Asia through coupling regional and global models
}

\author{
Meiyun Lin ${ }^{\mathrm{a}, *}$, Tracey Holloway ${ }^{\mathrm{a}}$, Greg R. Carmichael ${ }^{\mathrm{b}}$, \\ Arlene M. Fiore ${ }^{\mathrm{c}}$, \\ ${ }^{a}$ Center for Sustainability and the Global Environment, Nelson Institute for \\ Environmental Studies, University of Wisconsin-Madison, Wisconsin, USA \\ b Center for Global and Regional Environmental Research, University of Iowa, \\ Iowa City, Iowa, USA \\ c NOAA Geophysical Fluid Dynamics Laboratory, Princeton, New Jersey, USA
}

Supplementary Figures

Atmospheric Chemistry and Physics Discussion

* Corresponding author.

Email address: mlin26@wisc.edu (Meiyun Lin).

Published by Copernicus Publications on behalf of EGU.

25 December 2009 
(a) MOZART CO

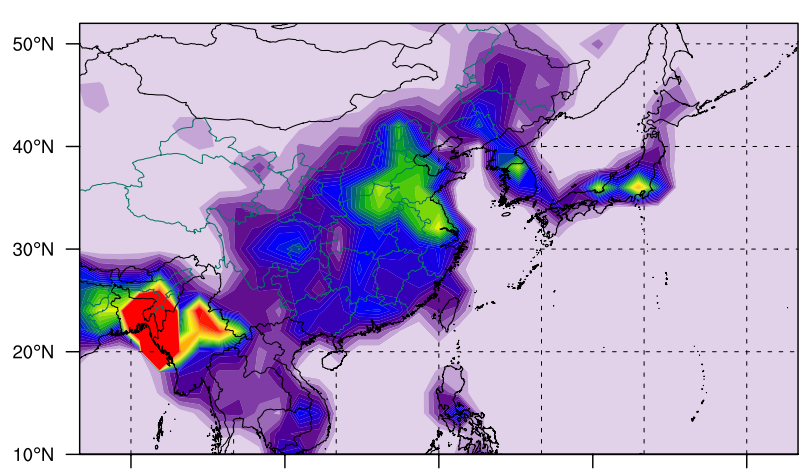

(c) MOZART $\mathrm{NO}_{x}$

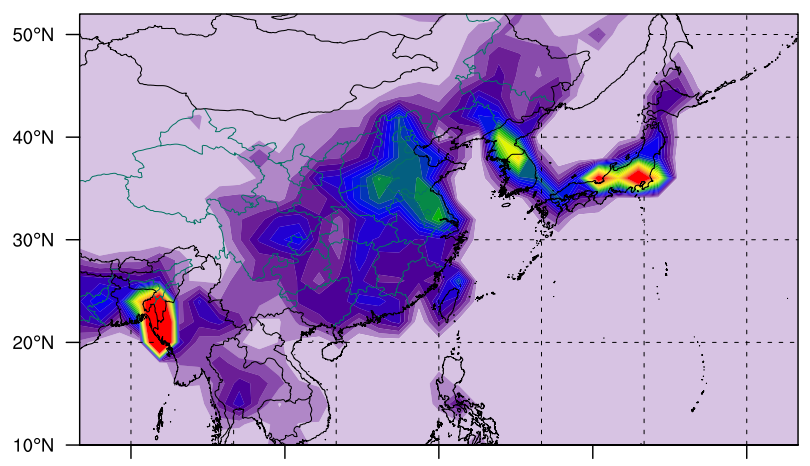

(e) MOZART Ethene

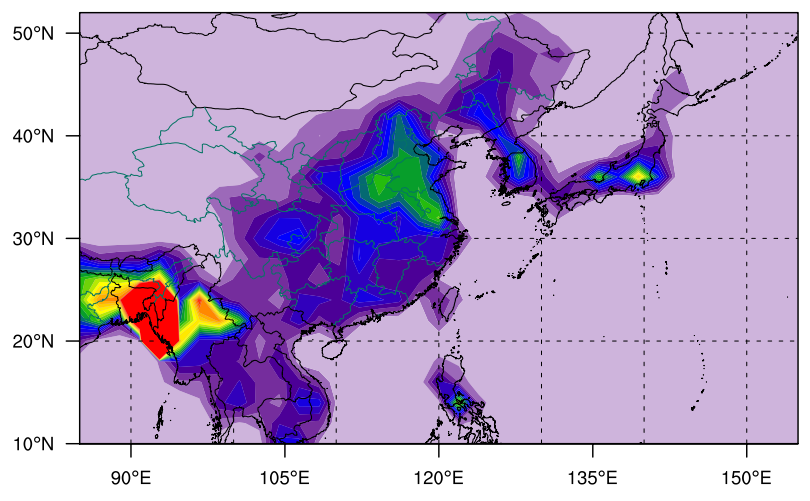

(b) WRF-Chem and CMAQ CO

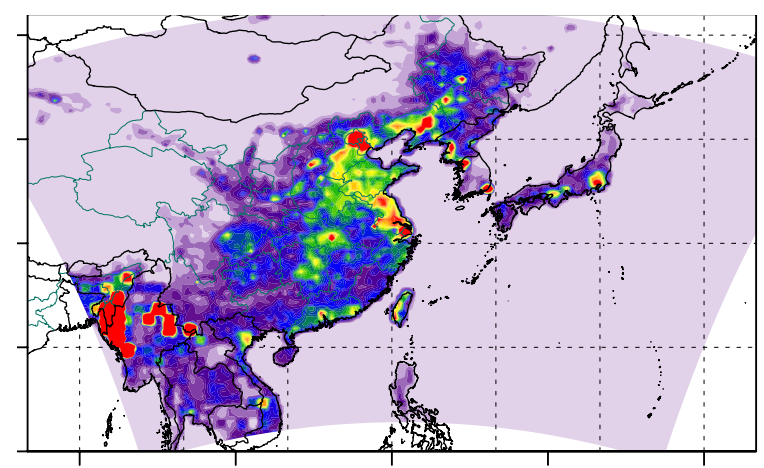

(d) WRF-Chem and CMAQ $\mathrm{NO}_{x}$

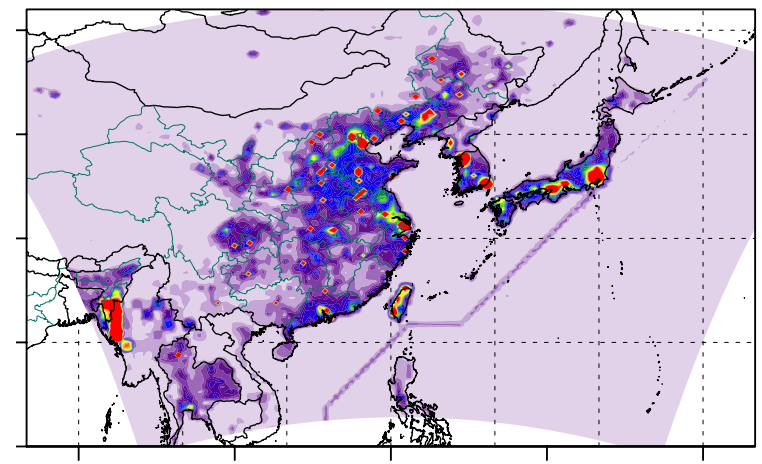

$\mathrm{moles} / \mathrm{km}^{2} / \mathrm{h}$

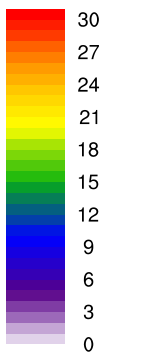

(f) WRF-Chem and CMAQ Ethene

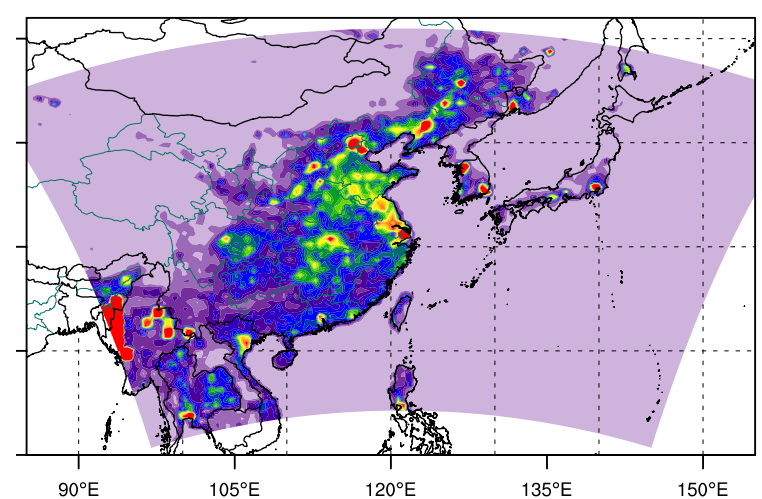

moles $/ \mathrm{km}^{2} / \mathrm{h}$

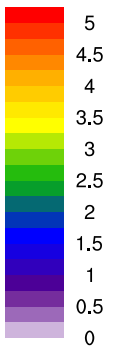

Figure S1. Comparison of MOZART, WRF-Chem and CMAQ anthropogenic (including biomass burning) emissions of $\mathrm{CO}, \mathrm{NO}_{x}$ and ethene during March, in units of moles $/ \mathrm{km}^{2} / \mathrm{h}$. WRF-Chem and CMAQ emissions are provided on a grid with resolution of $36 \mathrm{~km}$ x $36 \mathrm{~km}$; MOZART emissions are provided on a grid with resolution $1.9^{\circ} \times 1.9^{\circ}$. 
(a) ISOPRENE in WRF-Chem

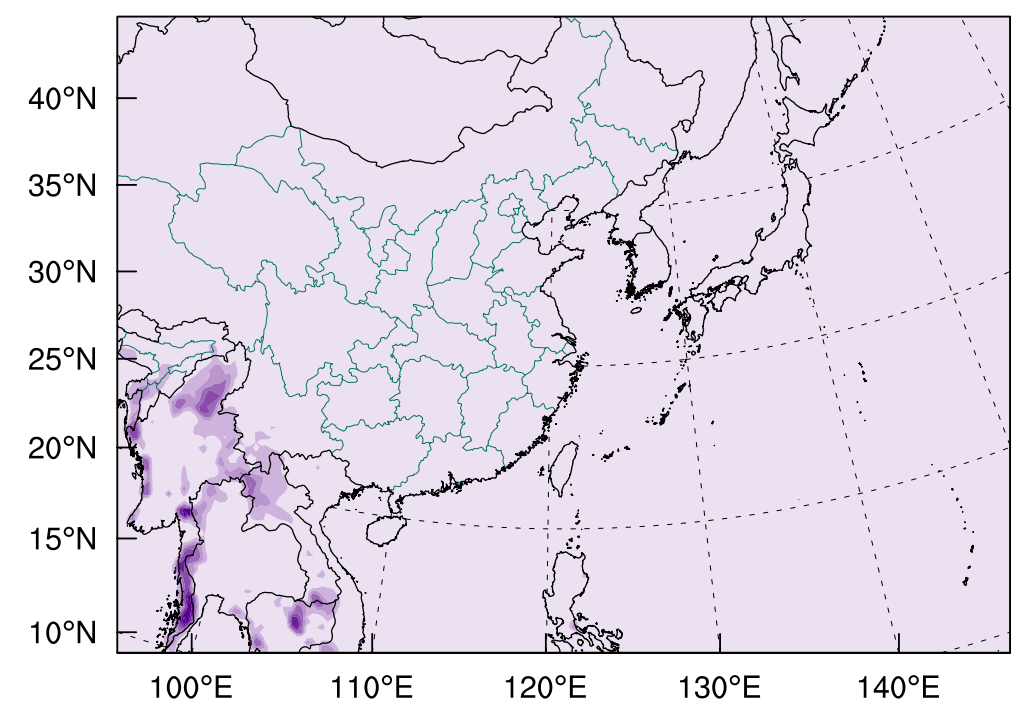

(b) ISOPRENE in CMAQ

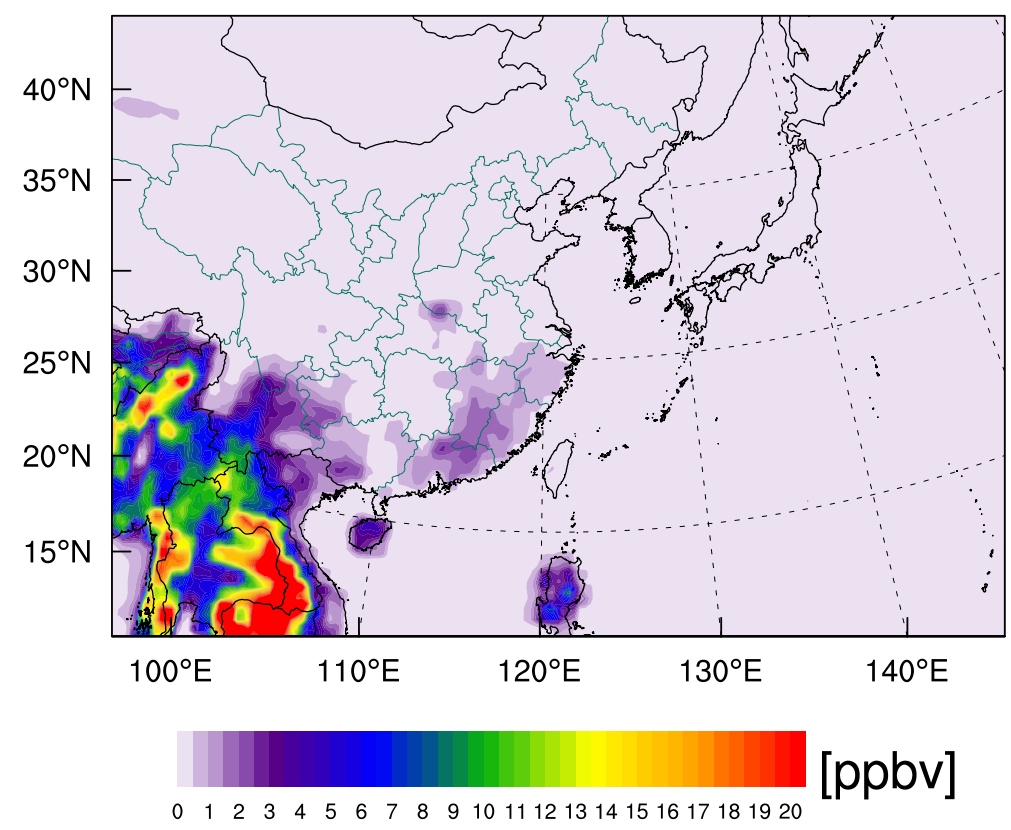

Figure S2. Monthly mean isoprene concentrations in CMAQ and WRF-Chem for March 2001. 

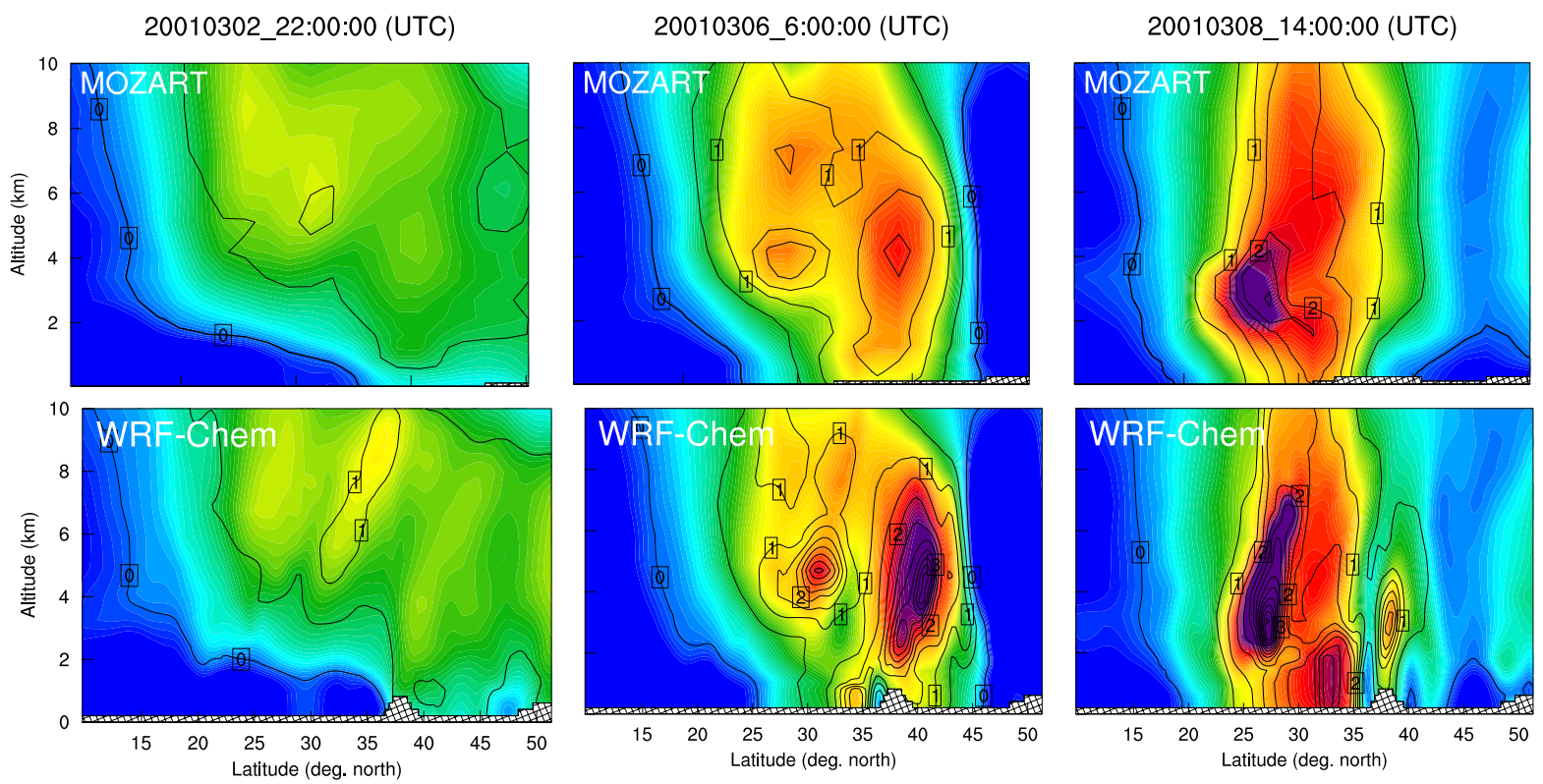

CO Flux Along $140 \mathrm{E}\left(10^{-10}\right.$ moles. $\left.\mathrm{cm}^{-2} \cdot \mathrm{s}^{-1}\right)$

$\begin{array}{lllllllllll}0 & 15 & 30 & 45 & 60 & 75 & 90 & 105 & 120 & 135 & 150\end{array}$

(a)

Figure S3. Comparison of MOZART and WRF-Chem simulated vertical profiles of CO and PAN zonal flux along $140^{\circ} \mathrm{E}$. PAN flux is shown as contours from 0.0 to 7.5 by $0.5 \times 10^{-9}$ moles cm $^{-2} \mathrm{~s}^{-1}$.
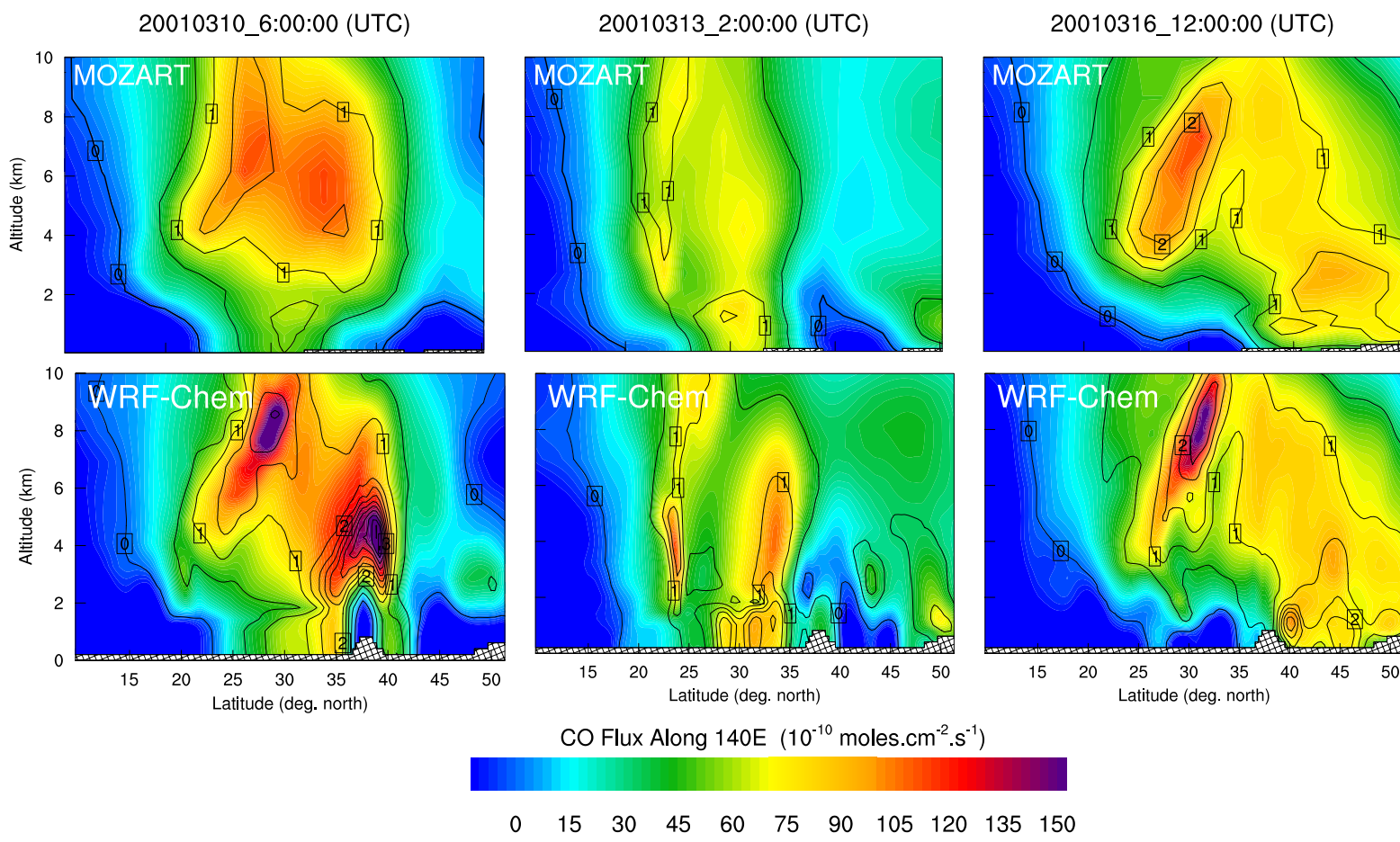

(b)

Figure S3. 


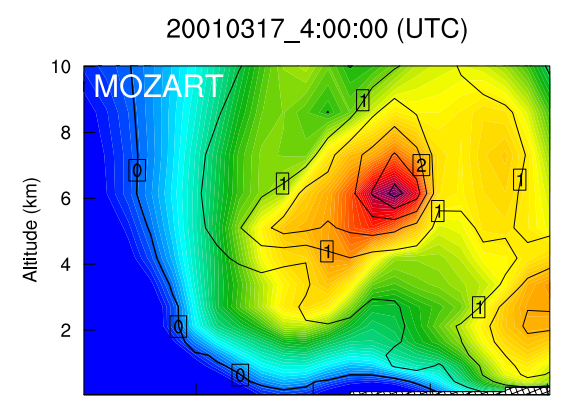

20010318_16:00:00 (UTC)
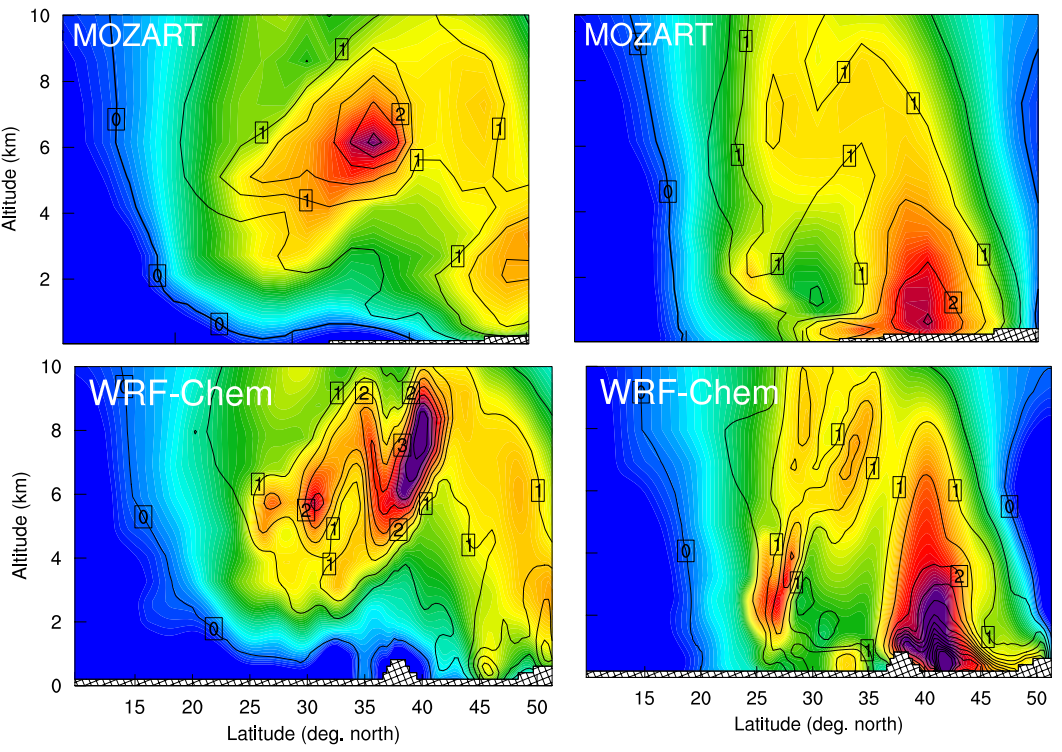
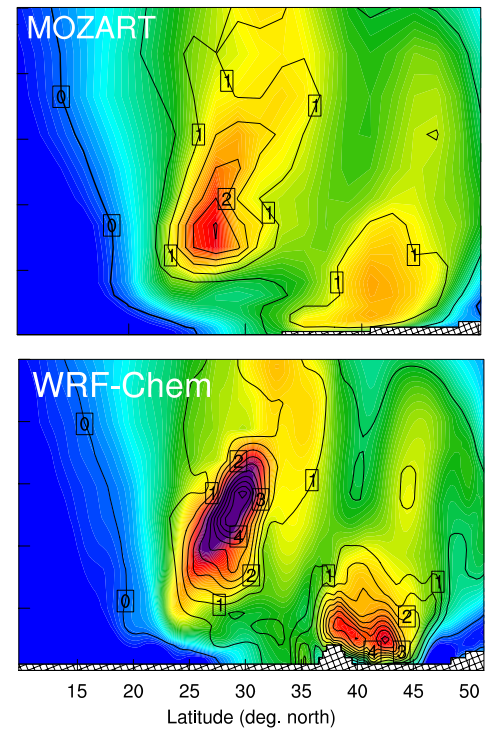

CO Flux Along 140E $\left(10^{-10}\right.$ moles. $\left.\mathrm{cm}^{-2} \cdot \mathrm{s}^{-1}\right)$

$\begin{array}{lllllllllll}0 & 15 & 30 & 45 & 60 & 75 & 90 & 105 & 120 & 135 & 150\end{array}$

(c)

Figure S3.
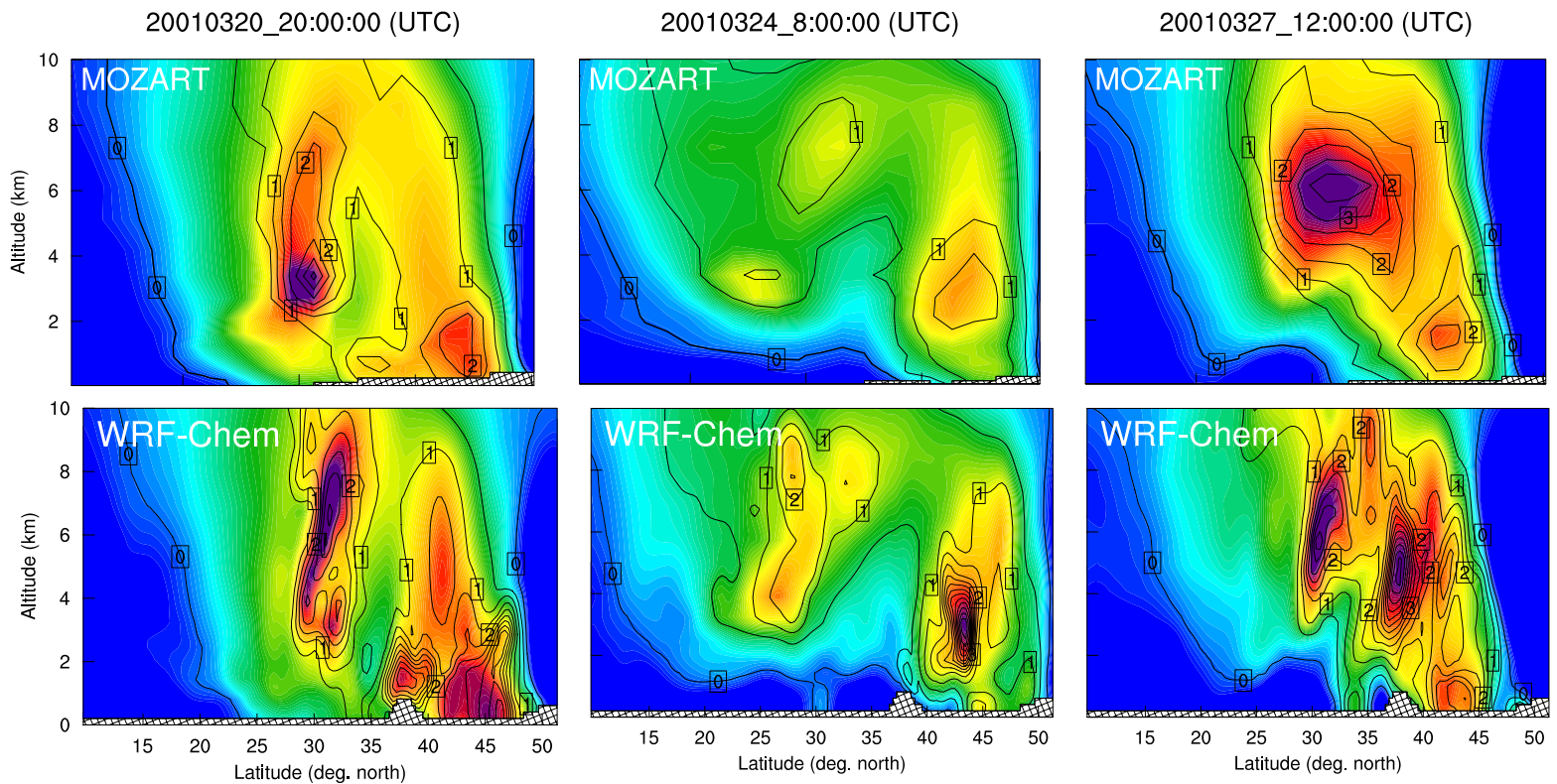

CO Flux Along 140E $\left(10^{-10}\right.$ moles. $\left.\mathrm{cm}^{-2} \cdot \mathrm{s}^{-1}\right)$

$\begin{array}{lllllllllll}0 & 15 & 30 & 45 & 60 & 75 & 90 & 105 & 120 & 135 & 150\end{array}$

(d)

Figure S3. 
(a) WRF-Chem with CBM-Z chemistry (mean=1.08ppbv)

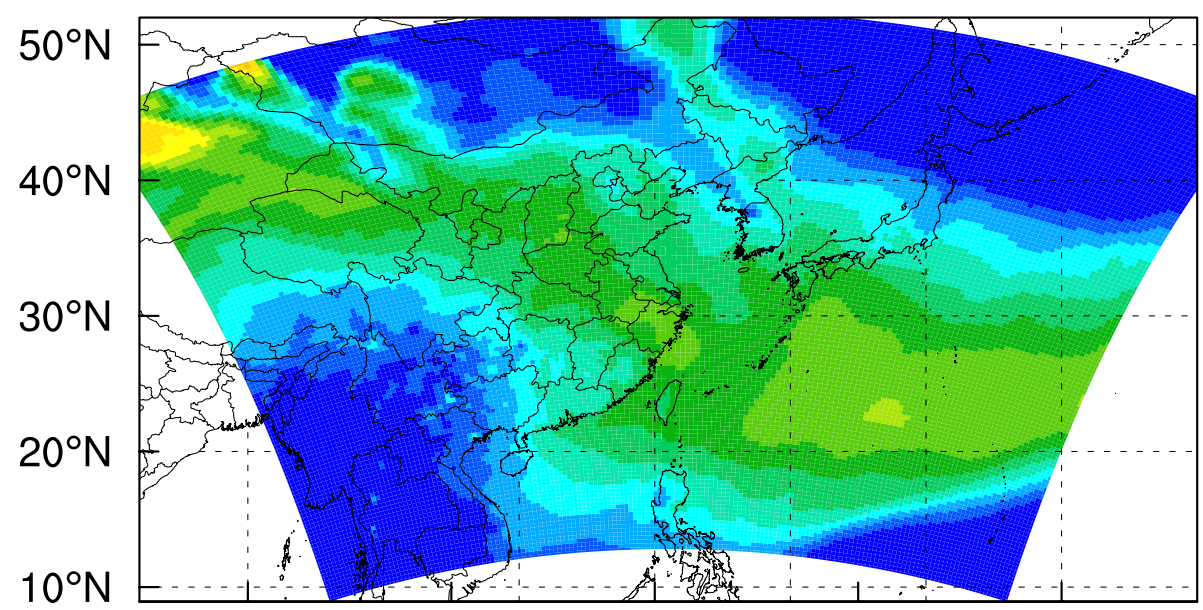

(b) WRF-Chem with RACM chemistry (mean=1.58ppbv)

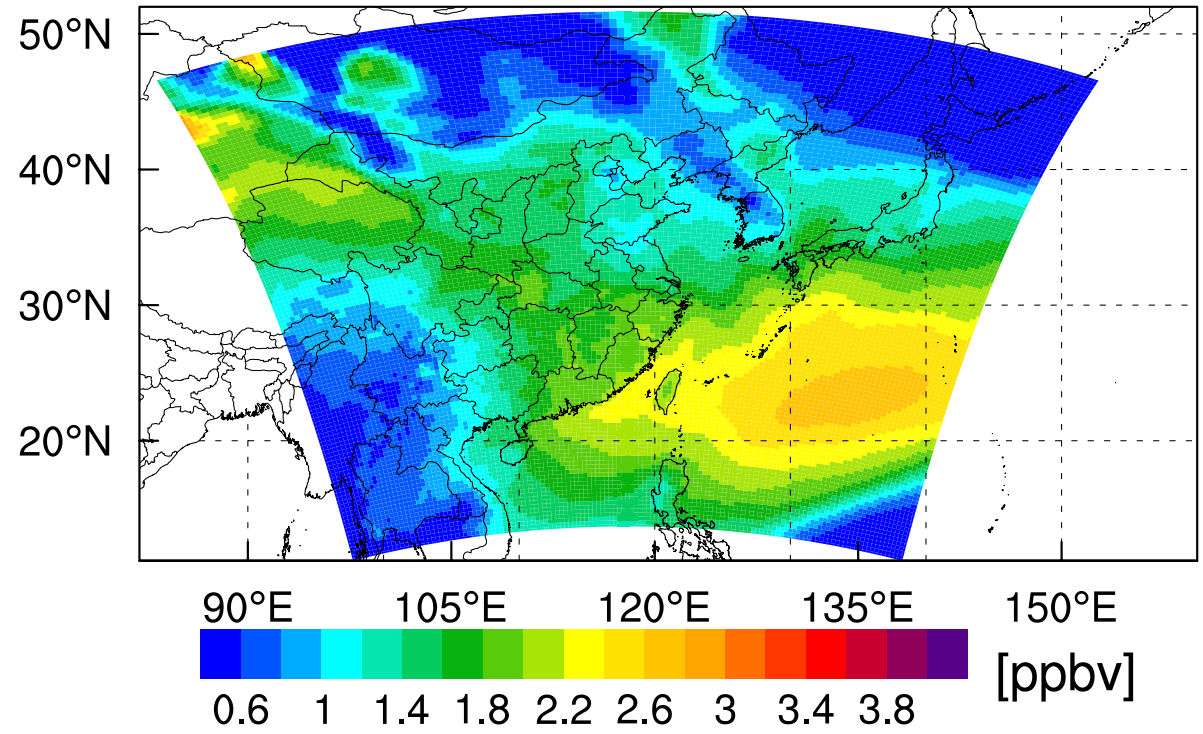

Figure S4. WRF-Chem calculated European enhancement on surface ozone in East Asia averaged over 1-15 March. 

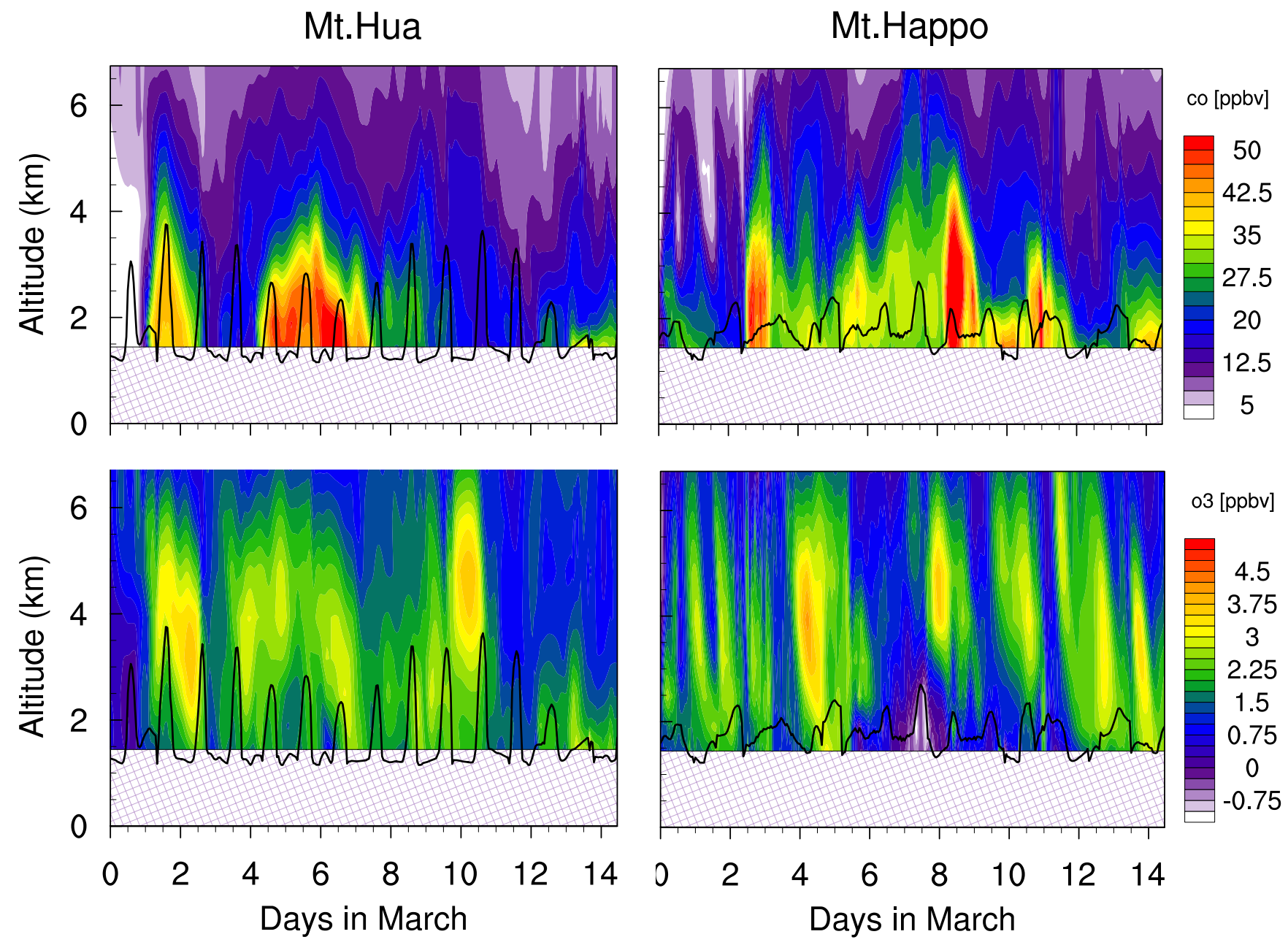

Figure S5. WRF-Chem calculated vertical profiles of European CO (upper panel), $\mathrm{NO}_{2}$ (middle panel) and $\mathrm{O}_{3}$ (lower panel) over China (Mt. Hua) and Japan (Mt. Happo) during 1-14 March. The black line shows the boundary layer depth. The hatched area indicates local terrain height. 